\title{
Anterior Chamber of the Eye
}

National Cancer Institute

\section{Source}

National Cancer Institute. Anterior Chamber of the Eye. NCI Thesaurus. Code C12667.

The space in the eye, filled with aqueous humor, bounded anteriorly by the cornea and a small portion of the sclera and posteriorly by a small portion of the ciliary body, the iris, and that part of the crystalline lens which presents through the pupil. (Cline et al., Dictionary of Visual Science, 4th ed, p109) 